\title{
Green Innovation and Income Inequality: A Complex System Analysis*
}

\author{
Lorenzo Napolitano ${ }^{1}$, Angelica Sbardella ${ }^{1,2}$, Davide Consoli ${ }^{3}$, \\ Nicolò Barbieri ${ }^{4}$, François Perruchas ${ }^{3}$ \\ ${ }^{1}$ Institute for Complex Systems, National Research Council, Rome \\ ${ }^{2}$ Institute of Economics, Sant'Anna School for Advanced Studies, Pisa \\ ${ }^{3}$ INGENIO (CSIC-UPV), Universitat Politècnica de València \\ ${ }^{4}$ Department of Economics and Management, University of Ferrara
}

July 3, 2020

\begin{abstract}
The objective of this paper is to analyse the relationship between income inequality and environmental innovation. We use a complexity-based algorithm to compute an index of green inventive capacity in a panel of 57 countries over the period 1970-2010. The empirical analysis reveals that, on average, inequality is detrimental to countries' capacity to engage complex green technologies knowledge bases. Using non-parametric methods allows us to further articulate this general finding and to uncover interesting non-linearities in the relationship between innovation and inequality.
\end{abstract}

Keywords: Complexity; Environmental Innovation; Inequality

*The authors are grateful to the anonymous referees for their insightful comments and suggestions to a previous version of this paper, and to the editorial board of the SPRU working paper series for their support. 


\section{Motivation and objectives}

The objective of this paper is to explore empirically the relationship between income inequality and environmental innovation. These two global challenges stem from different sources and manifest themselves in different ways, but are arguably tightly connected. On the one hand, the threat of climate-induced hazards calls upon systemic innovative responses that include, among other things, technological progress to accelerate the development or refinement of sustainable products and processes (Hoffert et al., 2002; Pacala and Socolow, 2004 (Popp et al., 2010)). One of the key analytical challenges in this debate concerns the identification of the circumstances that facilitate the green transition. On the other hand, empirical evidence indicates that, besides the widely-known negative distributional issues, income inequality can also hinder economic performance (see e.g. Forbes, 2000; Barro, 2000). An intriguing, and yet little explored, claim in this regard is that such the negative impact depends on the relative incidence of inequality on the income distribution (Voitchovsky, 2005). Further, income inequality and demand for environmental innovation exhibit similar patterns since countries that are likely to suffer the strongest negative effects of environmental degradation are also among the poorest (Mendelsohn et al., 2006; Bathiany et al., 2018), and often exhibit high levels of income inequality (Roberts, 2001). Last but not least, scholars have found evidence concerning a virtuous circle whereby innovation - not specifically green - exacerbates inequality (see e.g. Aghion et al., 2018) in a way that ultimately undermines the incentives to search and develop new technologies (Weinhold and Nair-Reichert, 2009).

The present paper analyses some unexplored aspects of the undeniably intricate connections between inequality and green innovation. First, most research focuses on the factors that favour the emergence of environmental technology (see Barbieri et al., 2016 for a review) but neglects the barriers that may prevent, or slow down, green innovation, with the exception of (Vona and Patriarca, 2011). The second gap in the literature is that green technologies are often treated as a homogeneous block and this stands in contrast with the huge diversity of goals they are designed for (Perruchas and Consoli, 2020), with the breadth of forms of know-how involved (OECD, 2011) as well as the differential stage of maturity each has achieved (Barbieri et al. 2020). Such a high degree of diversity is a peculiarity of this domain of (Barbieri et al., 2018) and obviously affects the distribution of green innovation capacity across countries (Sbardella et al., 2018).

Bringing together these insights, we address two research questions:

- What is the relationship between income inequality and countries' capacity to generate green innovation?

- Does this relationship vary by type of green technology?

To explore these issues, we analyse a panel of 57 countries over the period 1970-2010. To address the first question we propose regression analysis on a set of variables drawn from different sources. 
The dependent variable, green innovation capacity, is computed using the Economic Fitness and Complexity (EFC) algorithm on patent data (Tacchella et al., 2012; Cristelli et al. 2013). This recursive algorithm was originally designed to predict economic growth from country export data, and has been subsequently translated also to other domains, including innovation (Pugliese et al., 2019) and industrial sectors (Sbardella et al., 2017). The EFC algorithm has also been successfully applied to green innovation in a previous contribution (Sbardella et al., 2018), while Mealy and Teytelboym (2020) applied the Economic Complexity Index approach (Hidalgo and Hausmann, 2009) to study green productive capabilities. The EFC approach allows us to extract information from the bipartite network linking the countries included in the study to the spectrum of technologies (green and not) in which they have patented over time. By explicitly taking into account the complex structure of country-technology interactions, EFC enables us to differentiate countries not only according to the volume of green patents (as we would do by looking e.g. at patenting intensity) but also according to the composition of their patent portfolios - which is the footprint left behind by the unique capability accumulation path followed by each country. The main explanatory variable, income inequality, is built using information on net household income to calculate the Gini coefficient as well as various income percentile ratios. To address the second research question, we investigate whether the main result holds over the spectrum of green technologies (from the least to the most complex ones) and GDP.

The first key finding of our analysis, based on parametric regression, is that income inequality exhibits significant negative correlation with country green technology fitness ${ }^{1}$ On average, countries with high levels of inequality are also characterised by a lower level of green technology fitness: that is, their technological capabilities mainly cover a smaller number of green technological domains that are, also, less complex than others. This holds for different measures of income inequality including the Gini coefficient and other income percentile ratios. The second key finding, based on non-parametric multivariate NadarayaWatson regressions (Nadaraya, 1964), is that the relationship between inequality and green fitness is non-linear and, crucially, depends on GDP per capita levels. This brings to the fore a number of important nuances with respect to the first general finding, in short: (i) high levels of inequality are especially detrimental for more complex green technologies; (ii) a certain amount of inequality appear to be necessary for the development of complex capabilities underlying green technologies, especially in high income countries; (iii) low inequality opens up opportunities for countries with intermediate levels of per capita income to develop the specialise in relatively complex green technologies; (iv) inequality is almost always associated with less complex technologies, the arena where upper-middle income countries are plausibly more proactive.

\footnotetext{
${ }^{1} \mathrm{~A}$ negative relationship between a measure of complexity and income inequality was previously obtained by Hartmann et al. (2017); however here we focus on the green innovative competitiveness of countries, and employ the EFC algorithm applied to green technological fields rather than the ECI index (Hidalgo and Hausmann, 2009) based on product-level export data.
} 
The contribution of our study are manifold. First, we enrich the hitherto scant literature on barriers to environmental innovations, in this case income inequality. Second, by considering the complexity of green technology our analysis implicitly takes into account the heterogeneity of the attending increasing cost structure and uncertainties of the exploration process that leads to the generation of these technologies (Barbieri et al., 2018). This angle is coherent with the rationale of policy interventions aimed at enhancing cross-fertilisation and boundary spanning across domains on know-how. In the present paper we discuss whether these policy actions need to be coherent with a more comprehensive economic policy that tackles inequality. This is coherent with the emerging discourse concerning the interdependencies between items of the Sustainable Development Goals agenda, wherein both environmental sustainability and inequality are prominent (e.g. Freistein and Mahlert, 2016). Third, combining parametric and non-parametric approaches adds important nuances to the analysis of the non-linear relationship between inequality and green technological capacity. Previous work (e.g. Vona and Patriarca, 2011) finds that the link between the development of green technologies and inequality is moderated by the level of per capita GDP. Our non-parametric approach confirms this finding and adds to it by providing new insights into the combination of GDP-income inequality that exhibits stronger association with more complex technological capabilities.

The remainder of the paper is structured as follows. Section 2 provides a review of the relevant literature followed in Section 3 by details on the main data sources and variable construction. Section 4 presents the empirical analysis and the last section concludes and summarises.

\section{Theoretical background}

\subsection{The inequality innovation nexus}

Inequality and innovation are recurrent issues in the scholarly and policy domains, and so is their mutual relation. One strand of literature considers innovation as a determinant of inequality and emphasises unbalances in the structure of labour markets and of wages as the main vehicle. Technical change is known to have been traditionally biased in favour of more skilled workers and thus to accelerate the replacement of labour among the unskilled(Acemoglu, 2002) while skilled workers enjoy wage premia. The combination of these two processes has exacerbated inequality in several advanced economies, especially the US (Katz and Murphy, 1992). Aghion et al. (2018) contribute to this literature by looking at the distribution of income between labour and firm owners, and the rate of innovation. Their work provides theoretical and empirical support to the conjecture that innovation stimulates entrepreneurship but also increases income inequality. Indeed, the number of patents filed in US states is positively correlated to the top $1 \%$ income share. However, their results do not hold when broader measures of inequality are used, namely the Gini coefficient, Atkinson index, etc. 
A second strand of literature investigates the extent to which inequality is a barrier for innovation. Here, the income distribution affects the development and diffusion of technologies via a number of possible channels. From a demand-side perspective, in a more equal society innovation becomes more attractive thanks to the incentives for mass production goods. Weinhold and Nair-Reichert (2009) point out that, whereas the bottom and upper part of the distribution of income are more likely to demand, respectively, essential and customized products and services, middle class consumption generally concerns more standardized manufacturing goods, which strongly rely on incremental innovations. As observed by Sokoloff and Khan (1990), greater equality triggers, among other things, the efficient use of resources, scale economies and, in particular, the rate of inventive activities. This also implies that the mechanisms through which inequality affects innovation must be observed from a complementary supply side perspective. Khan and Sokoloff (2001) suggest that a higher level of market participation by population brings about opportunities for innovative activities. Over the past decades, the improvement of old products and the re-organisation of production in the US agricultural and manufacturing sectors were favoured by the high degree of involvement of the middle class (Khan and Sokoloff, 2001). Moreover, this broad market participation is linked to higher institutional quality - especially the protection of intellectual property rights - which made patenting simpler, cheaper and more accessible to US population in those years compared to other countries. The anecdotal evidence provided by these studies is confirmed by Weinhold and Nair-Reichert (2009), who investigate the direct role of the middle class share on patenting activities. Their insights highlight that a more equal income distribution and strong intellectual property rights protection positively affects patent filing by residents.

The foregoing debate has rarely touched upon environmental innovation but there are grounds to believe that a broadly similar set of mechanisms are in place. At the same time, the public good nature of environmental quality improvements entails that inequality is perceived as influencing innovative activities aimed at tackling local environmental problems, rather than global ones (e.g. urban PM10 reduction vs. global emissions). According to the demand-driven innovation approach, two main channels exist. The first is the so-called "pioneer consumer" effect whereby high-income consumers increase the demand for initially more expensive green products. In so doing they stimulate the production of this type of goods, thus leading to price reduction which, eventually, enables low-income consumers to add these products to their basket. The second effect is "consumption polarization", in which case excessive income difference between high and low income consumers reduces the potential externalities just mentioned. The seminal study by Vona and Patriarca (2011) points out that the relationship between inequality and the development of green innovative goods is highly non-linear: at low levels of percapita income the pioneer consumer effect prevails, whereas at high level of per-capita income the reverse occurs. They also explore this empirical relation on a panel of OECD countries and find that inequality appears less detrimental for innovative activities at the beginning of their life-cycle, which is in line with the pioneer consumer effect. 


\subsection{The complexity of technological developments}

The channels through which inequality affects innovation may lead to heterogeneous effects in relation to the type of technology under investigation (i.e. green vs. non-green) and/or the socio-economic conditions of the attendant countries (e.g. high, middle, low income countries). This research, however, neglects the characteristics of knowledge and how they moderate the inequality-innovation relationship. This gap is significant with regards to our understanding of green technologies. Barbieri et al. (2018) study to what extent green technologies differ from non-green ones on a set of patent indicators employed as a proxy for complexity, novelty and impact of future technological advances. They find that green patents perform better in all the dimensions considered in the study compared to their non-green counterparts. The higher complexity of green technologies implies higher costs and more uncertain knowledge recombination process which, in turn, leads to a potential underinvestment in the development of green technologies and calls for policy intervention aimed at cross fertilisation and boundary spanning. In this framework the investigation of the determinant of this more complex knowledge base seems to justify research questions that tackle this issue. In a study on the diffusion of green technologies across countries, Sbardella et al. (2018) emphasise that dealing with more complex portfolios of green technologies requires more advanced invention competences. From this it follows that, on average, high-income countries be endowed with more developed capabilities and thus be more likely major inventors of complex technologies. This resonates with recent findings on the spatial distribution of complex activities, taken as a whole and not necessarily related to specific (i.e. environmental) domains (Balland and Rigby, 2017).

In the present study, we investigate whether and to what extent the correlation between innovation and inequality varies according to the complexity of the country's portfolio of green technologies. That is, we explore whether inequality represents a barrier to innovation in countries where the difficulty to produce different kinds of green knowledge is higher. By recalling the mechanisms depicted above, higher inequality provides less incentives to engage in more complex green innovative activities via a demand effect. In order to identify whether the pioneer consumer effect or the consumption polarisation mechanism dominates, it is crucial to account for the efforts spent in developing less and more complex green technologies. On the one hand, we expect inequality to be associated with less complex green technological capabilities due to the lower incentive to develop more complex technological solutions which require inventors to face higher cost and uncertainty in the knowledge generation process. On the other hand, inequality may represent a barrier also to more complex technologies. However, this relationship may depend on the level of GDP. That is, a certain level of inequality may be necessary to provide the incentive to develop more complex capabilities, in line with the pioneer consumer effect. However, extremely high levels of inequality, especially in high income countries, may negatively affect the economic returns of more complex capabilities due to 
a lower a demand effect.

\section{Data and variable construction}

For this study we create a panel of up to 57 countries for the period 1970-2010. The main variables measure green innovation capacity, income inequality and country characteristics. The choice of the time periods is contingent upon the availability of data, primarily on green patents and income inequality. We rely on a variety of sources that are described in greater detail below.

\subsection{Fitness complexity approach}

The data employed for the empirical exercises is derived from several sources. In particular, the main dependent variable, country green technology fitness, is constructed by combining the raw patent data extracted from the PATSTAT database of the European Patent Office (EPO) with specific information about environment-friendly technologies collected by the OECD in the environment-related catalogue (ENV-TECH) (Haščič and Migotto, 2015). PATSTAT aggregates tens of millions of patent documents from over one hundred national and regional patent offices. These report, for each patent, the date of filing, the country of residence of inventors and applicants, the patent family (i.e. the group of patents that share the same priority filing and can be assumed to refer to the same invention), and a set of standard technology codes that classify the fields of technology in which the patent application introduced innovations with respect to the existing prior art at the time of filing.

For our analysis we use the Cooperative Patent Classification (CPC), a hierarchical classification that allows to represent the technological spectrum at various resolutions. However, as detailed as the CPC classification can be, it is not, in isolation, the best tool to highlight green technologies. In fact, technology classifications have the primary objective of allowing patent office examiners to easily search prior art in order to assess the originality of applications; for this reason, though the classification hierarchy groups similar technologies together, it has a hard time keeping track of the uses of each technology, which tend to vary over time. The ENV-TECH catalogue comes to our aid in this respect by grouping $\mathrm{CPC}$ codes that are relevant for green innovation in a hierarchy. This allows us to tweak the CPC classification and partition the technological space at any given level of disaggregation in a set of green classes and another set of non-green classes.

We exploit the recursive nature of the EFC algorithm, which defines the technological fitness of a country as a function of the complexity of the technologies in which it innovates and the complexity of a technology as a function of the fitness of the countries that produce them. In so doing we are able to consistently rank the elements of both sets 


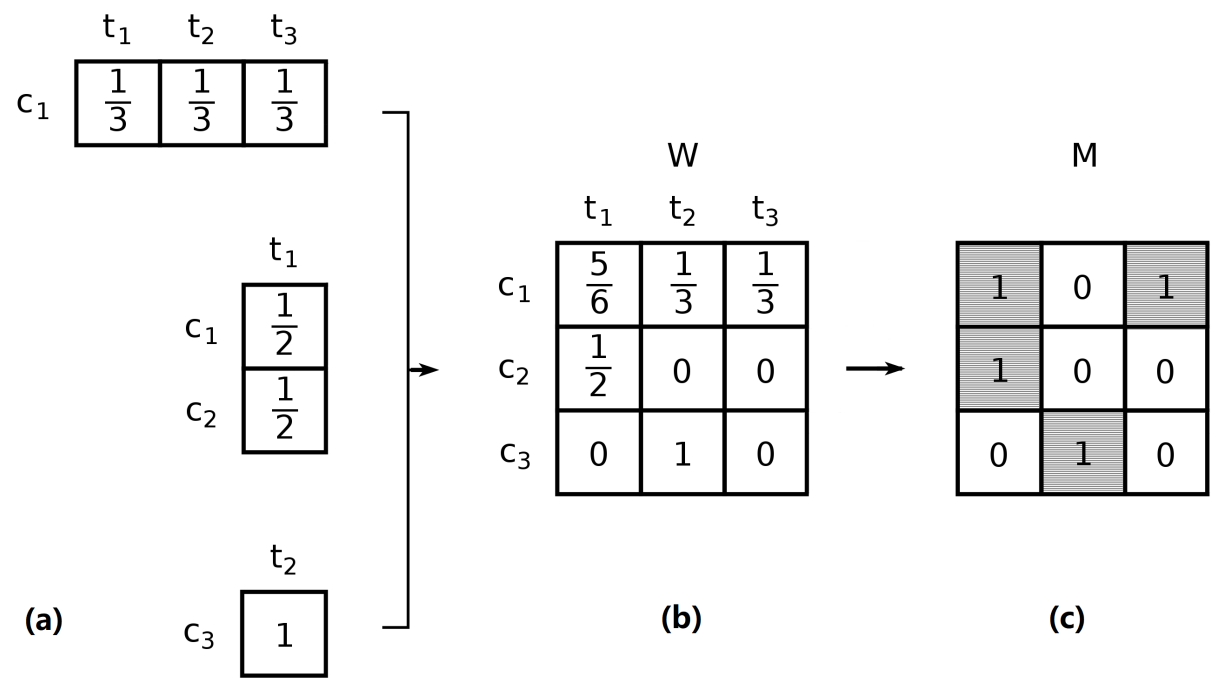

Figure 1: Construction of a binary data matrix for period y. Panel (a): each patent family is attributed a unit of weight, which is equally split among all combinations of inventor countries and technological codes included in patent applications belonging to the family which were filed during period y. Panel (b): a weighted matrix (W) is built in which rows correspond to countries and columns correspond to technology codes; every (country, technology) pair is attributed the corresponding sum of patent family shares. Panel (c): W is binarized creating matrix $\mathrm{M}$, which is then fed to the EFC algorithm. 
and thus to tell more and less complex technologies apart. The EFC algorithm is part of a larger, and growing, literature based on the application of methodologies inspired by complexity science to a diverse array of empirical issues ranging from macroeconomic forecasting (Hidalgo and Hausmann, 2009; Tacchella et al., 2018), the analysis of the evolution of countries' productive structures (Hausmann et al., 2007; Hidalgo et al., 2007; Zaccaria et al., 2014), the relation between complexity and inequality (Hartmann et al., 2017; Sbardella et al., 2017), to the assessment of capability accumulation and interaction in shaping knowledge creation as well as technological progress (Pugliese et al., 2017, Napolitano et al., 2018). Indeed, it has been shown that technological capabilities are generally nested Napolitano et al. (2018); this implies that countries with a very specialized R\&D output will mostly innovate in more ubiquitous (and hence mundane) technological fields ${ }^{2}$

In order to apply the EFC algorithm to our data and obtain a measure of the green fitness of countries, we need to represent the set of country-technology relations that exist at any moment in time as a bipartite graph. To this aim, we assume that every patent family is a separate invention and assign it one unit of weight for every year in which at least one new patent has been added to it. For each year, we split the unit weight of the family equally among all combinations of technology code and inventor country that appear in that year. Repeating the procedure for all active patent families year by year, we obtain a measure of the observed innovation intensity of each country in each technological field that we summarize in a weighted matrix W (see Figure 1 for an example). We then binarize the weighted matrix $\mathrm{W}$ through Revealed Comparative Advantage (Balassa, 1965 ${ }^{3}$ and obtain M such that:

$$
M_{c, t}(y)= \begin{cases}1 & \text { if } \frac{W_{c, t}}{\sum_{t^{\prime}} W_{c, t^{\prime}}}>\frac{\sum_{c^{\prime}} W_{c^{\prime}, t}}{\sum_{c^{\prime}, t^{\prime}} W c^{\prime}, t^{\prime}} \\ 0 & \text { otherwise. }\end{cases}
$$

The binary matrix $\mathrm{M}$ is then fed to the EFC algorithm, which is defined as follows:

$$
\begin{cases}\widetilde{F}_{c}^{(n)}=\sum_{t} M_{c, t} Q_{t}^{(n-1)}, & Q_{t}^{(n)}=\frac{\widetilde{Q}_{t}^{(n)}}{<\widetilde{Q}_{t}^{(n)}>} \\ \widetilde{Q}_{t}^{(n)}=\frac{1}{\sum_{c} M_{c, t} \frac{1}{F_{c}^{(n)}}}, & F_{c}^{(n)}=\frac{\widetilde{F}_{c}^{(n)}}{<\widetilde{F}_{c}^{(n)}>}\end{cases}
$$

\footnotetext{
${ }^{2} \mathrm{~A}$ corollary to the above is that countries that are able to advance knowledge in more complex (exotic) fields, and thus achieve higher fitness, are able to innovate across the technological spectrum.

${ }^{3}$ The sparsity of the data matrices ensures that results are robust to the choice of the binarization strategy.
} 
with initial condition:

$$
\sum_{t} Q_{t}^{(0)}=1 \forall t
$$

The key ingredients of the recursive EFC algorithm are the Fitness of countries $(\mathrm{F})$ and the complexity of technologies (Q). In particular, $\mathrm{F}$ is the average complexity of the technologies produced by a country, while $\mathrm{Q}$ is, for each technology, a non-linear function of the fitness values of the countries that include that technology in their baskets. Non-linearity plays a crucial role in this context because the main term in defining the complexity of a technological field is the least fit country that innovates in that field. The underlying rationale is that the fitness of a country captures the competitive advantage that the underlying endowment of capabilities accrues. The more diverse the set of capabilities, the more complex is the technology space available to the country. Conversely, a country with low fitness has less capabilities and, therefore, is limited to less complex technological domains. Depending on the structure of the input matrix, the EFC algorithm is known (Pugliese et al., 2016) to converge to zero fitness and zero complexity at different speeds for different countries and technologies respectively. However, this is not an issue because it is always possible to define a consistent ranking along both dimensions. For this reason, our main dependent variable is the fitness ranking and not the fitness scores of countries. The same is true for technological complexities, which we employ to tell more complex technologies apart from less complex ones in the second part of the empirical analysis.

To illustrate, assume that a breakthrough in human mobility is possible due to progress in electric self-driving vehicles (henceforth technology Z). Further, assume that two essential ingredients for the viability of next-generation car technology are effective machine learning algorithms (technology X) as well as reliable energy-dense batteries (technology $\mathrm{Y}$ ). Technology $\mathrm{Z}$ will likely be developed in the countries that have capabilities to innovate in technologies $\mathrm{X}$ and $\mathrm{Y}$. From the EFC perspective, $\mathrm{Z}$ is more complex than the sum of its building blocks, $\mathrm{X}$ and $\mathrm{Y}$, if the set of countries that innovate in $\mathrm{Z}$ is smaller than the set of countries that innovate in $\mathrm{X}$ or $\mathrm{Y}$. 4

Figure 2 displays a binary country technology-matrix, in which rows and columns have been ordered using the EFC algorithm. Rows represent countries in decreasing order of fitness from top to bottom, while columns are ordered to reflect increasing technological complexity from left to right. The matrix displays the characteristic nested structure in which higher fitness countries tend to be more diversified and lower fitness countries are strong innovators in a subset of the fields in which higher-fitness countries are strong (see Tacchella et al., 2012 for country-product matrices and Sbardella et al., 2017 for

\footnotetext{
${ }^{4}$ Notice that nothing is said about the intricacy of the inventions that rely on technology Z. In fact, a modern petrol engine has a far grater number of moving parts and components than an electric engine. Nevertheless, the technology for an electric self-driving car would be more complex than a traditional oil-fueled vehicle because far less countries would be able to develop the former technology.
} 


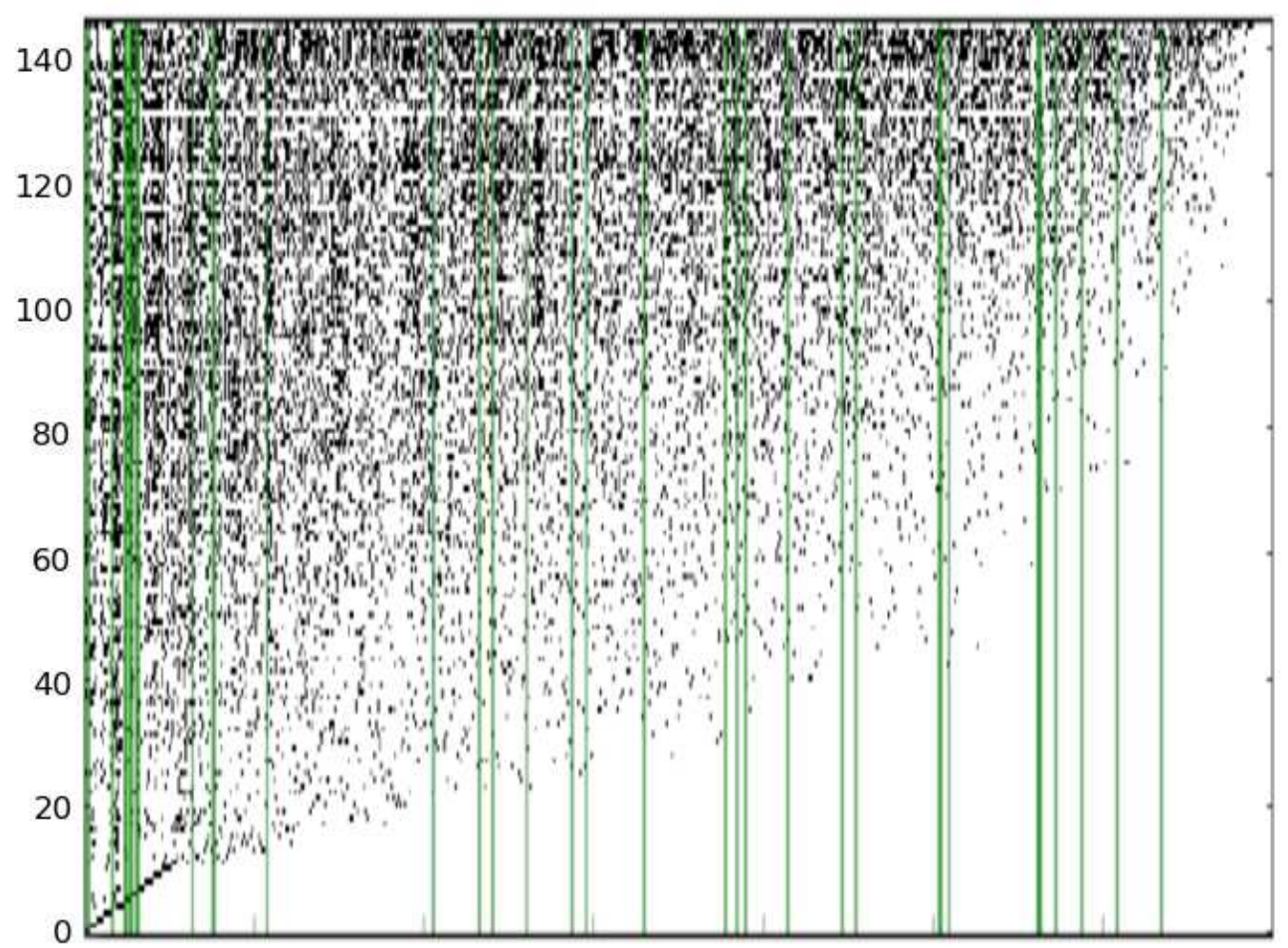

Figure 2: Country-Technology matrix with rows and columns ordered using the EFC algorithm. Countries are displayed along the rows with fitness decreasing from top to bottom; technological fields are depicted along the columns with complexity increasing from left to right. Green technologies correspond the green shaded lines.

region-industrial sector matrices displaying a similar nested structure). Consequently, the probability of finding rare technological fields, which supposedly require the most advanced capabilities, increases as fitness increases. The columns in the matrix represent the full spectrum of CPC and ENV-TECH codes available in the data, so countries in the figure are ordered by technological fitness. In order to compute country-specific green technological fitness, we consider only the complexity of the ENV-TECH codes (shaded in green). Notice that green technologies are quite spread out over the entire technological spectrum, meaning that they range from very low to relatively high values of complexity.

Last but not least, Figure 3 shows the distribution of inventive efforts across countries as captured by the fitness ranking of countries. This broad brush picture indicates that environmental innovative activities are relatively more intense (brighter green) in North 


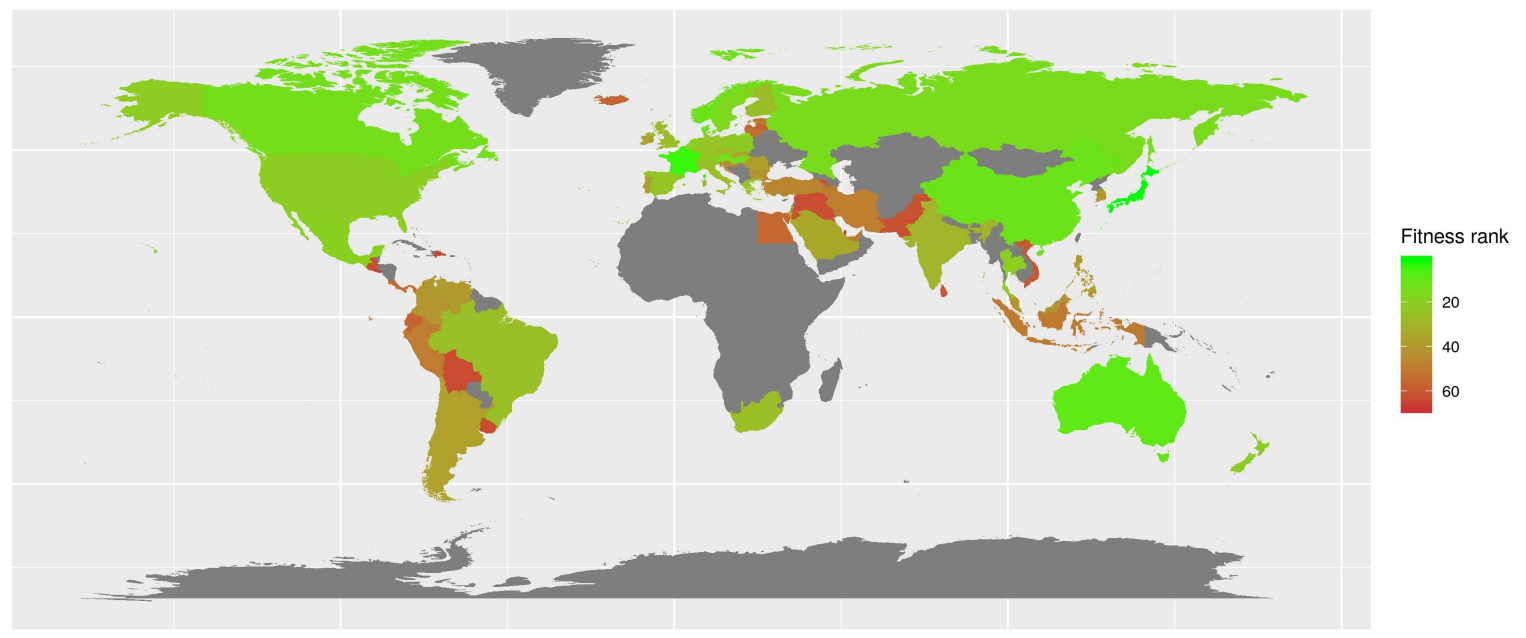

Figure 3: Geographic distribution of the Green Fitness Ranking across countries. Colour coding: bright green (top of the ranking), brown (middle) to red (bottom). Grey: no data available.

America, Europe, Russia, China, Japan, and Australia, while countries in Latin America and in the Middle East are in the mid to bottom part of the ranking (brown to red).

\subsection{Income inequality and other dimensions of interest}

The main explanatory variable in our regression analysis is income inequality. To build this, we retrieve information on household net income from the World Income Inequality Database (WIID)5, which covers 179 countries over the period 1867-2012. For the purposes of the present paper, we compute five measures of income inequality for each country. The first is the Gini coefficient, a widely used proxy of inequality with wide geographical data coverage. Since a major goal of this paper is to look into differences between various portions of the income distribution, we also extract from the WIID information on deciles of disposable income, and compute the following ratios: ninth to first decile (90:10); eighth to second (80:20); seventh to third (70:30); sixth to fourth (60:40). We envisage that this ample selection of variables affords a more nuanced understanding of the extent of different levels of inequality across the board.

To account for unobserved country characteristics, we include a battery of variables into our empirical analysis, namely: GDP per capita (source: World Bank ${ }^{6}$ ), the percentage of population with tertiary literacy (source: Barro-Lee $]^{7}$ ) and population density

\footnotetext{
5 https://www.wider.unu.edu/project/wiid-world-income-inequality-database (Last access: 28 January 2019)

${ }^{6}$ https://data.worldbank.org/indicator/NY.GDP.MKTP.CD (Last access: 28 January 2019)

${ }^{7}$ http://www.barrolee.com/data/full1.htm (Last access: 28 January 2019)
} 
(source: World Bank ${ }^{8}$ ). To ensure coherence across the data, we build averages over five-year intervals of all the variables under analysis. While this is dictated by the format of the data on literacy, which is only available at that frequency, taking averages over periods allows us to account for the fact that green innovation, inequality, and the other dimensions under analysis change slowly over time.

\section{Analysis}

\subsection{Economic Fitness, Green Innovation and Inequality}

Figure 4 provides details about the evolution over time of the ranking of green technologies based on their complexity. To ensure consistency with the rest of the empirical analysis, the rankings are computed over 5-year time windows, with the first observation covering the period 1970-1974 and the last observation covering the 2005-2009 window. Technological complexity decreases from top to bottom. The left and right y-axes report the complexity rankings relative to the first and last time window respectively. For ease of visualization, the y-labels and plot lines are coloured to reflect their position in the oldest ranking. The mix of the label colours along the right y-axis shows that the complexity of technologies has varied substantially over the time period.

In the upper third of the ranking are domains that have maintained their leadership, namely Enabling Technologies for GHG Mitigation [8.3], Environmental Monitoring [1.5], and Rail Transport [6.2], as well as technological fields that have caught up, in particular Road Transport Technologies [6.1], Nuclear Energy [4.4], and Technologies for the processing of minerals (used in industrial production, e.g. cement, glass) [9.4] . All these instances of technologies that have worked their way up the ranking speak to the extent to which new and advanced capabilities have kept pouring into the attendant fields since the 1970s. In contrast to these, there are domains that have lost prominence, for example Supply-Side Technologies for Water Availability [2.2], or Enabling Technologies for Greenhouse Gas Mitigation [9.8]. Further notice that, on the one hand, transitions from low- to high complexity can be rather abrupt, as in the case of Road Transport Technologies [6.1] while, on the other hand, movement along the ranking need not be monotonic as shown by Supply-Side Technologies for Water Availability [2.2] and Energy Generation From Fuels Of Non-Fossil Origin [2.2], which display a highly variable degree of complexity. On the whole, this ranking resonates with empirical studies on the life cycle of green technology, whereby established fields like Renewable Energy Generation [4.1] are in the bottom third reflecting how mature the attendant knowledge base is and, relatedly, how ubiquitous is that technology. In contrast, Capture/Disposal of GHG other than Carbon Dioxide [5.2]

\footnotetext{
${ }^{8}$ https://data.worldbank.org/indicator/EN.POP.DNST (Last access: 28 January 2019)

${ }^{9}$ The full list of ENV-TECH Green Technologies codes and labels is available on Table 3 in the Appendix.
} 


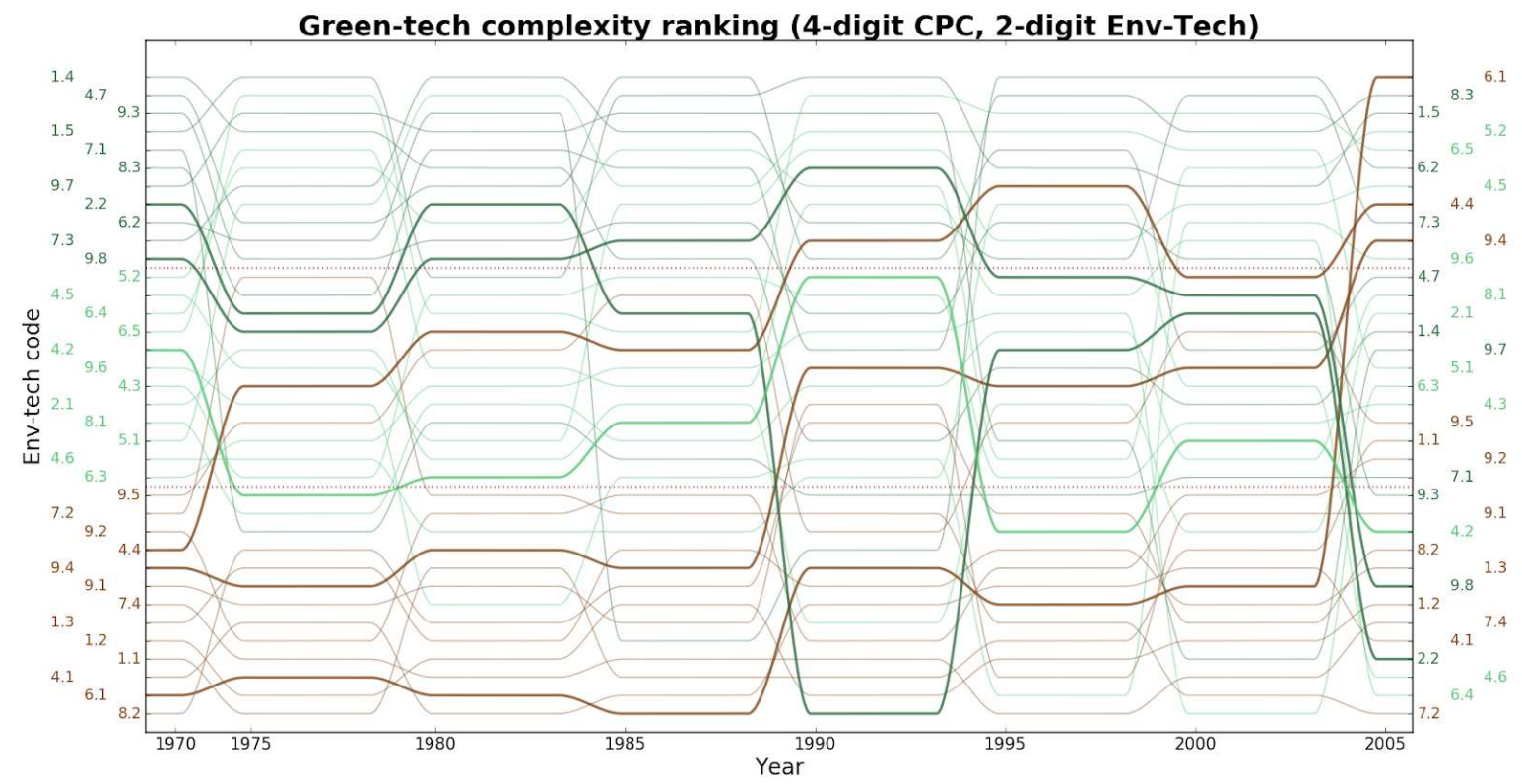

Figure 4: Time evolution of the Complexity Ranking of green technologies (5-year timewindows). Higher ranked (more complex) technologies at the top.

is still at relatively early stage of development, and thus exhibits higher complexity and less ubiquity (see Barbieri et al., 2018).

Figure 5 builds on the former technology ranking and plots the time trajectory of all the countries included in the analysis along the fitness ranking. Similar to Figure 4, each observation refers to 5-year intervals starting in 1970, country labels are coloured according to the corresponding fitness ranking in the first window and countries with higher fitness are displayed at the top. Notice that, contrary to technologies, country ranking positions are more stable and that where they take place changes in ranking are less abrupt. This is intuitively plausible considering that while imitation in mature fields of technologies can lead to quick catching up by capability-poor countries, the global set of capabilities that defines a country's technological reach is the result of a long-term accumulation process, which can therefore generate some inertia in the fitness values and the relative performance. Two notable exceptions in our sample are Portugal (PT), the United Arab Emirates (AE) and Panama (PA), all of which display relatively high variability in the central time periods with the first two leaping to the top all at once between 2000-2004 and 2005-2009 and the latter stabilizing at the bottom. Further notice that the relative stability of the green fitness ranking does not mean that no long-term trends can be observed. For example, Israel (IL) and the United States of America (US) start high up in the ranking and constantly drop, while China $(\mathrm{CN})$ gradually reaches the top. Note in passing that some lower fitness countries are not always present in the plot, but appear 


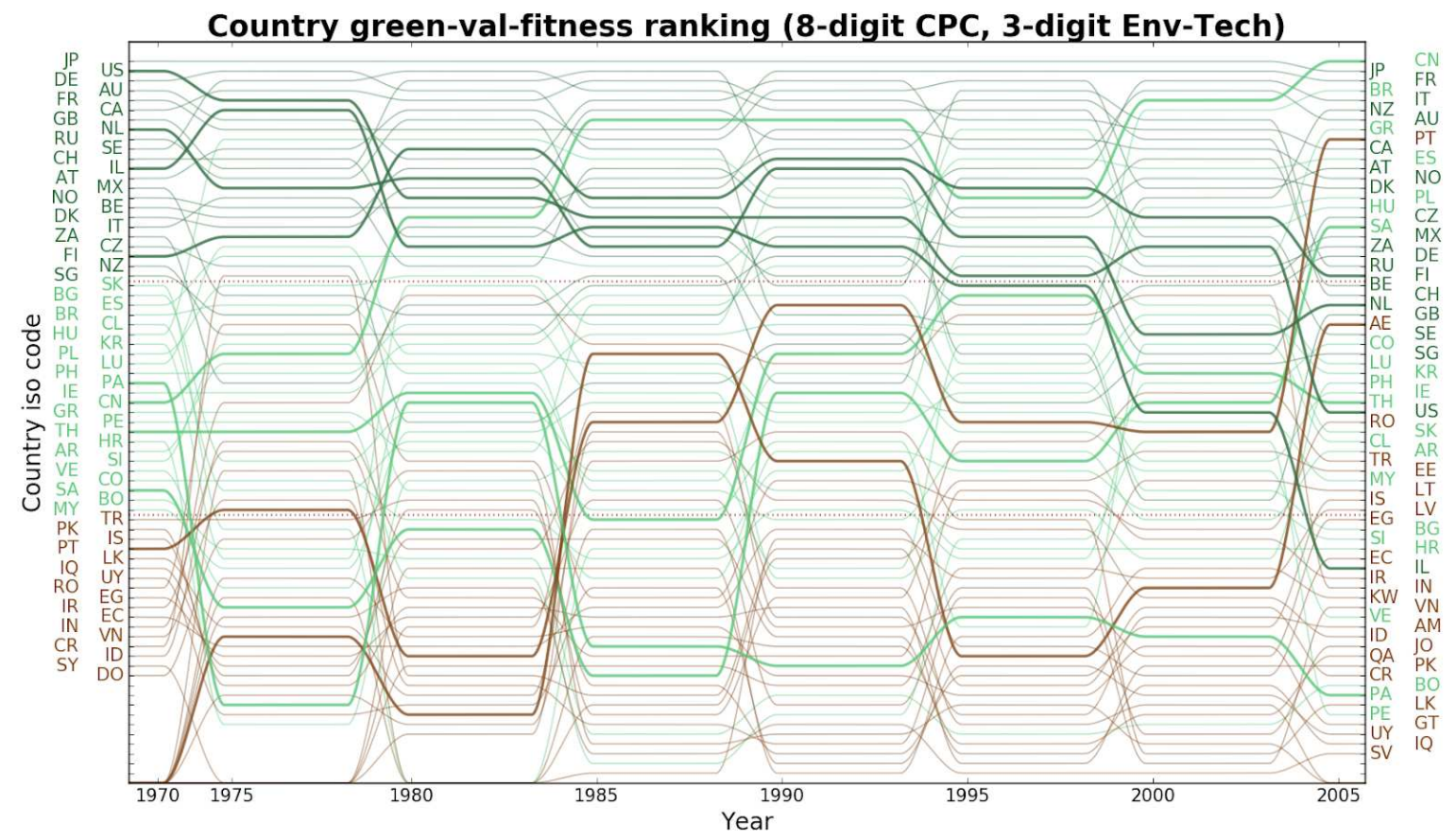

Figure 5: Time evolution of the green fitness of countries (5-year time-windows). Higher ranked (higher fitness) countries at the top.

only when their first green patents are recorded.

\subsection{Parametric approach}

In this section, we explore the relationship between environmental-related technological complexity and income distribution by means of parametric regression analysis. The empirical strategy investigates whether there is a significant correlation between countries' green fitness and income inequality over the period 1970-2010. Our dependent variable is country green technological fitness, described in Section 3. Further, we articulate the relationship between country green fitness and income inequality by assessing whether the results hold for the entire spectrum of technologies or the finding is peculiar to green technologies. The main independent variable is within-country income distribution measured using the Gini coefficient or the decile ratios 90:10, 80:20, 70:30 and 60:40. As mentioned, given the low pace at which inequality evolves over time (Quah et al., 2001), we employ 5 -year time windows. The model we estimate also includes country fixed effects and a set of controls such as population density, per capita GDP, and a measure of schooling (i.e. the percentage of population with tertiary literacy). Finally, country-specific time trends are included to control for unobservable variation over time and across countries.

Table 1 shows the results of the model estimation. The main finding is that there is 
a negative and significant association between a country's income inequality and green fitness. This means that countries with higher levels of inequality reduce the incentives to develop more complex capabilities related to green technology. According to the literature, higher complexity is associated with higher costs and uncertainty in the development of new technologies. In this context, inequality plays a pivotal role by exacerbating the expected returns from innovative activities. Such an association is confirmed when we use the Gini index and the income distribution ratios 90:10 and 80:20 as a proxy for income inequality. It is worth noting that this result takes into account the intensity of the inventive activities in each technological domain and the complexity of technological fields.

Table 1: Parametric regression results - Green technology fitness

\begin{tabular}{|c|c|c|c|c|c|}
\hline & (1) & $(2)$ & $(3)$ & (4) & (5) \\
\hline Gini (ln) & $\begin{array}{l}-8.748^{* *} \\
(3.629)\end{array}$ & & & & \\
\hline $90: 10$ & & $\begin{array}{c}-0.126^{* *} \\
(0.0492)\end{array}$ & & & \\
\hline 80:20 & & & $\begin{array}{l}-0.424^{* * *} \\
(0.125)\end{array}$ & & \\
\hline $70: 30$ & & & & $\begin{array}{l}-4.143 \\
(3.192)\end{array}$ & \\
\hline $60: 40$ & & & & & $\begin{array}{l}-7.929 \\
(8.894)\end{array}$ \\
\hline$G D P p c$ & $\begin{array}{l}2.956^{* * *} \\
(0.698)\end{array}$ & $\begin{array}{l}2.920^{* * *} \\
(0.888)\end{array}$ & $\begin{array}{l}2.892^{* * *} \\
(0.860)\end{array}$ & $\begin{array}{l}2.791^{* * *} \\
(0.962)\end{array}$ & $\begin{array}{l}3.012^{* * *} \\
(0.915)\end{array}$ \\
\hline Pop Density & $\begin{array}{l}-0.0607 \\
(0.0756)\end{array}$ & $\begin{array}{l}0.00424 \\
(0.205)\end{array}$ & $\begin{array}{l}-0.0158 \\
(0.185)\end{array}$ & $\begin{array}{c}-0.0182 \\
(0.203)\end{array}$ & $\begin{array}{c}-0.0493 \\
(0.198)\end{array}$ \\
\hline Schooling & $\begin{array}{l}0.0736 \\
(0.134)\end{array}$ & $\begin{array}{c}-0.0413 \\
(0.212)\end{array}$ & $\begin{array}{l}0.0616 \\
(0.125)\end{array}$ & $\begin{array}{l}0.00539 \\
(0.222)\end{array}$ & $\begin{array}{l}0.0712 \\
(0.161)\end{array}$ \\
\hline Country FE & Yes & Yes & Yes & Yes & Yes \\
\hline Time trends & Yes & Yes & Yes & Yes & Yes \\
\hline $\mathrm{R} 2$ & 0.593 & 0.614 & 0.632 & 0.601 & 0.606 \\
\hline $\mathrm{N}$ & 273 & 199 & 207 & 198 & 207 \\
\hline
\end{tabular}

Further, we explore whether this association holds also for all types of technologies 
grouped together. Table 2 shows that the coefficients of the inequality measures are not statistically significant when we consider all the technologies developed in a specific country. This result suggests that inequality might act as a barrier especially when green technological capabilities are concerned, and this effect might be due to the higher complexity that characterises this group of technologies. However, a non-linearity may affect these findings. In the next section we explore these patterns through a non-parametric approach that enables us to observe this relationship at each level of inequality, green fitness, and GDP per capita.

Table 2: Parametric regression results - Total technology fitness

\begin{tabular}{llllll}
\hline & $(1)$ & $(2)$ & $(3)$ & $(4)$ & $(5)$ \\
\hline Gini (ln) & -6.074 & & & & \\
& $(4.784)$ & & & & \\
90:10 & & -0.0423 & & & \\
& & $(0.0579)$ & & & \\
80:20 & & & -0.135 & & \\
& & & $(0.143)$ & & \\
70:30 & & & & 4.393 & \\
& & & & $(5.650)$ & \\
r60:40 & & & & & 9.383 \\
& & & & & $(12.67)$ \\
GDP pc & -0.582 & $0.800^{*}$ & $0.601^{*}$ & 1.282 & $0.789^{*}$ \\
& $(1.051)$ & $(0.459)$ & $(0.334)$ & $(0.908)$ & $(0.458)$ \\
Pop Density & 1.153 & -1.012 & -0.982 & -1.081 & -1.012 \\
& $(1.015)$ & $(0.944)$ & $(0.917)$ & $(1.010)$ & $(0.948)$ \\
Schooling & -0.592 & 0.322 & 0.215 & 0.345 & 0.149 \\
& $(0.503)$ & $(0.415)$ & $(0.306)$ & $(0.444)$ & $(0.281)$ \\
Country FE & Yes & Yes & Yes & Yes & Yes \\
Time trends & Yes & Yes & Yes & Yes & Yes \\
\hline R2 & 0.184 & 0.618 & 0.621 & 0.620 & 0.622 \\
N & 280 & 204 & 213 & 203 & 213 \\
\hline
\end{tabular}

Notes: Dependent variable is mean total technology Fitness per country per year. Country fixed effects and time trends are included in the model. Robust standard errors in parenthesis. ${ }^{*} p<.1,{ }^{* *} p<.05$, $* * * \quad p<.01$ 


\subsection{Non-parametric approach}

In this section, we explore the relationship between inequality and green technology fitness using a non-parametric approach. Figure 6 depicts a graphical tool to visualise qualitatively the joint relation between green technological capabilities as proxied by green fitness, GDP per capita, and the proposed measures of income inequality (Gini coefficient, the 90:10, 80:20, 70:30 and 60:40 income decile ratios). In particular, each panel of Figure 6 represents a colour-map of the relation between income inequality on the $\mathrm{x}$-axis, the logarithm of GDP per capita on the y-axis, and a non-parametric estimate of the green fitness ranking on the z-axis. The values of the latter are captured by different shades of green such that the darker the green the higher the fitness. To build this figure, we pool all the countries and years in our panel and take 5-year moving averages of the aforementioned variables to ensure coherence across the data. The colour-maps are obtained via a multivariate Nadaraya-Watson regression (Nadaraya, 1964), a continuous non-parametric method, with a Gaussian kernel. In practice, we estimate the conditional expected value of the dependent variable, the green fitness ranking, given the independent variables, GDP per capita and income inequality, by calculating locally weighted averages of the green fitness ranking, where the weights are Gaussian kernels.

Figure 7 shows the standard errors of the Nadaraya-Watson means: herein, the darker areas correspond to a standard error of $4 \%$ or above, while the white ones to a standard error of $2 \%$ or less. To allow comparability, the iso-levels of the green fitness ranking estimations are superimposed on the plots in Figure 6. In the upper portion of the plot, irrespective of their income inequality level, countries with high levels of per-capita income display generally high levels of green fitness. This is not surprising considering that high-income countries are more likely endowed with more developed capabilities, therefore income inequality is likely to constitute less of a barrier to producing knowledge in complex technologies.

An interesting feature of the plots in Figure 6 is the diagonal movement of colour, which hints at an interplay between income inequality and GDP per-capita in contributing to the green fitness ranking. The figures suggest that there is a threshold of GDP per-capita below which it is unlikely that a country will be able to develop a sufficient number of complex technologies to obtain high green fitness. Countries located in the upper left corners of the plots in Figure 6 are characterised by high GDP per capita and low income inequality; they are therefore expected to achieve the highest positions in the green fitness ranking. Low income inequality lowers such threshold and allows also countries with intermediate levels of per capita income to develop the capabilities necessary to increase their capacity to innovate in relatively complex green technologies and thus achieve intermediate levels of green fitness.

Put otherwise, a country's wealth might not be a barrier to developing advanced competencies for environmental innovation insofar as income inequality is not too high. This

offers a qualitative hint at the fact that a more equal distribution of income matters for 

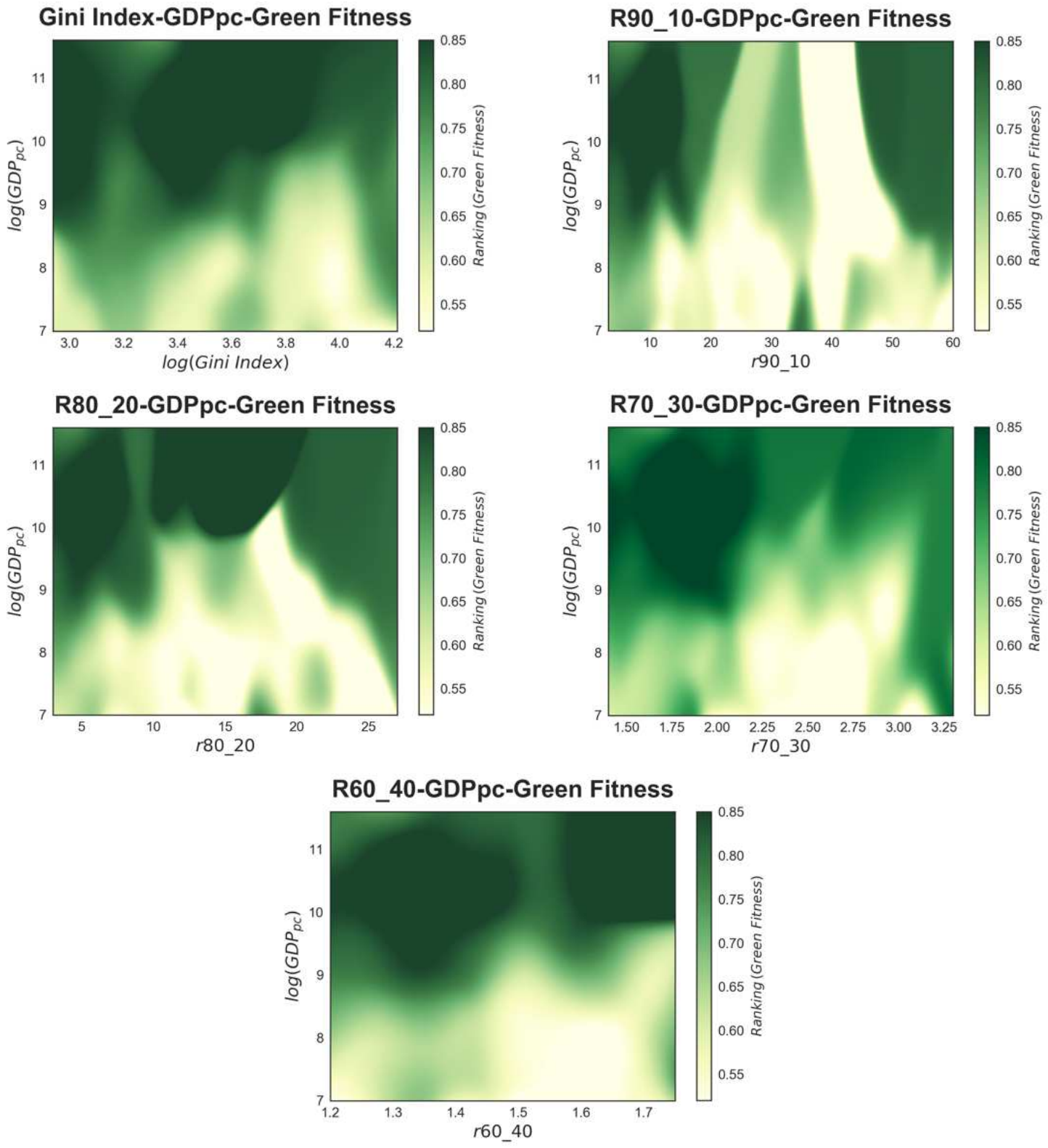

Figure 6: The three-dimensional relation between different measures of income inequality namely the logarithm of Gini index, and the 90:10, 80:20, 70:30 and 60:40 income decile ratios - on the x-axis, the logarithm of GDP per capita on the y-axis, and the ranking of green fitness on the z-axis. Each colour map represents the expected value of green fitness given the income inequality measure and GDP per capita and is obtained with a non-parametric Nadaraya-Watson kernel estimation by pooling all countries and years in our database. 
unleashing innovation capacity among both low- and mid-level income countries. Hence, high income inequality appears to be a barrier for innovation capacity among both lowand mid-level income countries. Notice that the evidence is consistent when we take as measures of inequality the intermediate income decile ratios, the top and bottom ratios, and the Gini coefficient. The only apparent exception is the 90:10 ratio case; however, looking at the standard error of the estimation in Figure 5, we see that the significant regions of the green fitness ranking estimation are placed only in the left and in the uppermiddle quadrants of the r90:10- $\log \left(G D P_{p} c\right)$ plane, where the colour pattern is consistent with that of the other inequality measures. This suggests that the dark green region in the upper right portion of the 90:10 graphs are mostly artefacts of the non-parametric estimation technique.

To provide some context on these maps, we superimpose on the generic terrain of Figure 6 the coloured trajectories of Brazil, China, Portugal, the Netherlands, and the US (Figure 8). The trajectories are built selecting three points in time - the initial, middle and final observation of the country in question - and each trajectory is composed of two arrows pointing in the direction of time. By allowing to observe the simultaneous effect of income per capita and inequality on green fitness, this plot complements the descriptive analysis of the country rankings in the previous subsection, where the performance in green innovation of emerging and advanced economies has been commented on. As expected, the combined growth of income per capita and the decrease of inequality from the starting to the final point in time lead to an increase in green fitness. Only the US (in orange) departs from this behaviour: while remaining among the top green innovators, its Gini index increases over time. Indeed, for the US, which has already developed a very advanced set of capabilities and is able to produce the most complex green technologies, inequality does not seem to have a detrimental effect on innovative capacity.

\section{Concluding remarks and the way ahead}

The objective of this paper was to analyse whether income inequality may act as a barrier to environmental innovation. These two global challenges stem from different sources and manifest themselves in different ways, but are arguably tightly connected. Indeed, they exhibit similar incidence across space, whereby countries that are most exposed to the perils of environmental degradation are also among the poorest, and often suffer high levels of income inequality. Innovation, it has been argued, is the other main channel that links together environmental sustainability and inequality. Empirical evidence indicates that progress in technology is a key tool, albeit not the only one, to preserve the environment while maintaining high levels of economic performance. However, research has also convincingly demonstrated that innovation can be a trigger of inequality which, eventually, undermines the ability to develop new technologies. Closer insights into how

inequality and the environment interact can inform policymakers and other stakeholders 

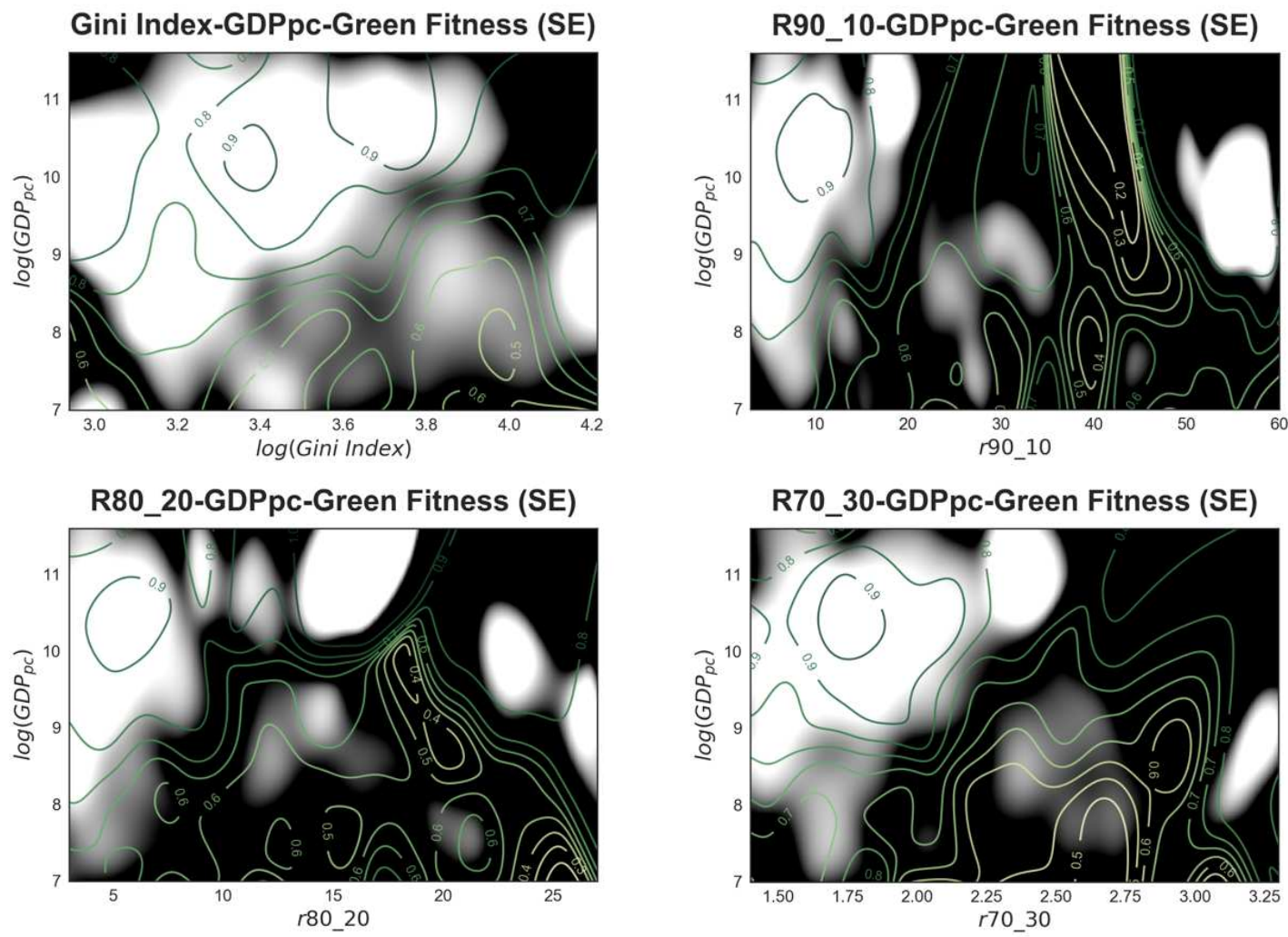

R60_40-GDPpc-Green Fitness (SE)

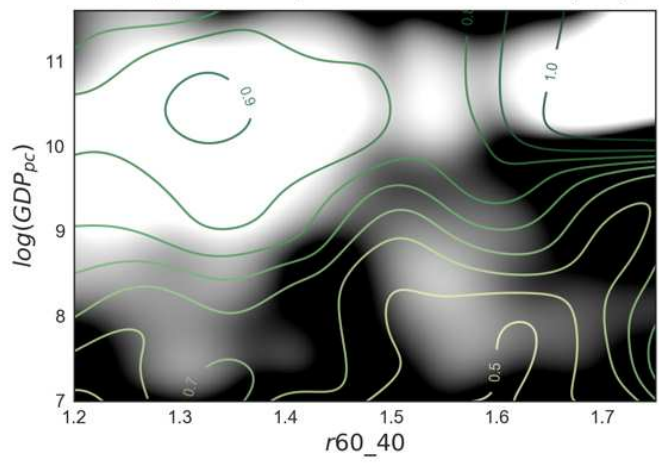

Figure 7: Estimation errors of the green fitness colour-maps in Figure 6. The plots are built with the same data as Figure 6. Two layers of information are represented in this figure. (1) In the black and white scale, the standard error of the green fitness ranking mean estimated through a the Nadaraya-Watson regression with Gaussian kernel. White indicates a standard error of $2 \%$ or less, and black a standard error of $4 \%$ or more. (2) In the green shades, the iso-lines of the green fitness ranking levels (lowest in light green, highest in dark green). The plot is obtained by pooling all countries and years comprising our database. 


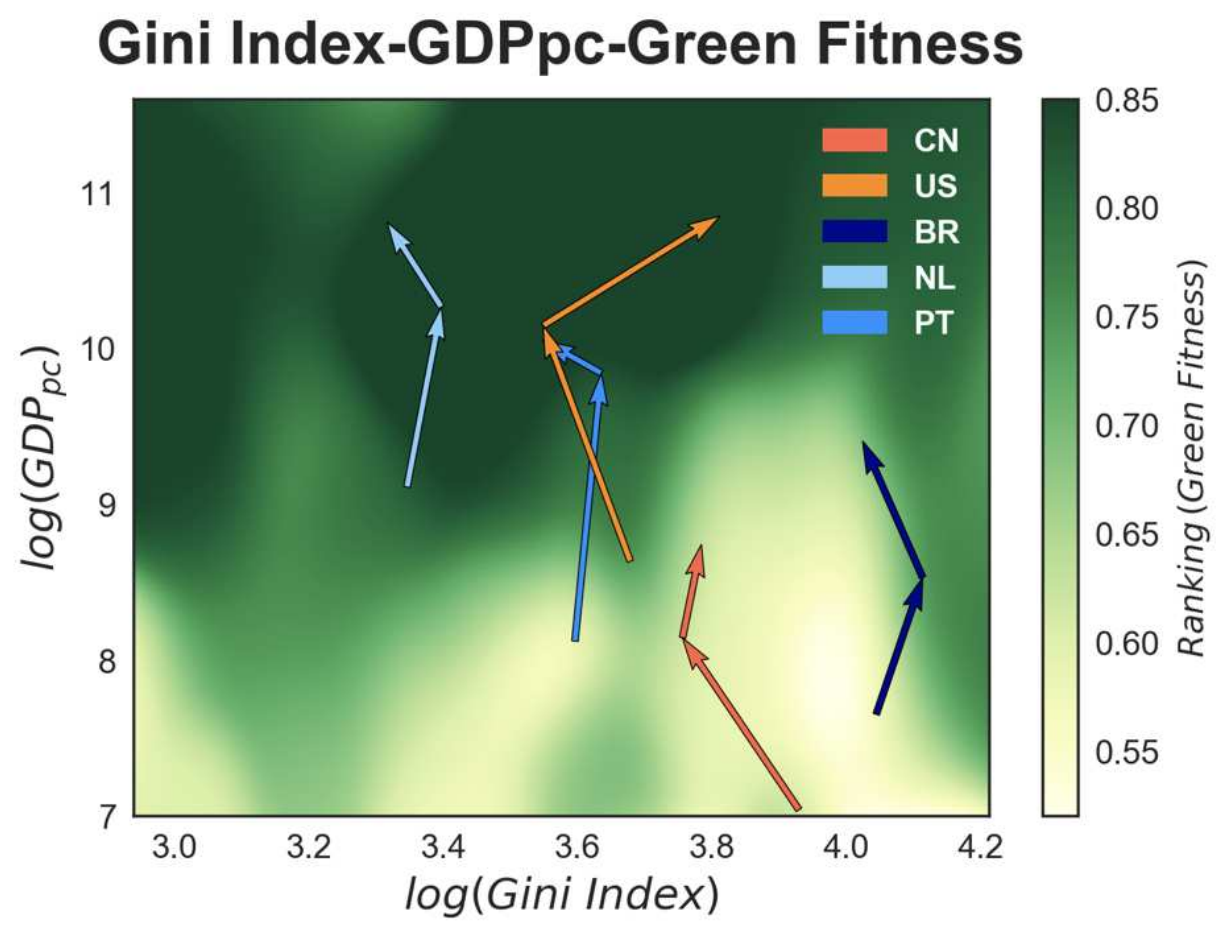

Figure 8: Gini index colour map with country trajectories. We superimpose on Figure 6 the trajectories of Brazil, China, Portugal, the Netherlands, and the US in the Gini index-GDP per capita plane. The arrows represent the initial, middle and final observation of the country in question, and point in the direction of time. 
involved in the design and the implementation of sustainable development.

While most literature insists on the factors that facilitate the emergence of new technology, we have addressed the little-explored issue of country specific circumstances that act as barriers to the pursuit of environmental innovation. In particular, we focus on the knowledge bases of countries to explore the extent to which domestic technological capabilities rely on complex green technologies. In so doing, we acknowledge the heterogeneity of green technology as regards both the domains of know-how and of application. To this end, we relied on economic complexity approaches to account for the diverse nature of technological specialisation and for how this distributes across different institutional domains like countries. In addition, the paper contributes to the debate on the linearity of the relationship between inequality and technological development. To do so, we employed both parametric and non-parametric approaches to delve deeper into this relationship at different levels of inequality and GDP per capita.

Taking advantage of the nested structure of green patenting data we apply a complexitybased measure, the EFC algorithm, to define a fitness measure of the green technological competitiveness of each country. Such an approach affords the opportunity to study the green technology portfolios of each country, and therefore to look beyond measuring patenting intensity in isolation. In so doing we gain detailed information on the global structure of country-technology interactions and are able to for the qualitative composition of inventive activities. Moreover, this method is consistent with the notion that innovating in any domain requires broad ensembles of specific and generic know-how as well as the ability to recombine these inputs. In short, innovation capacity goes hand in hand with the country's development path.

Of course, our analysis does not exhaust the potential applications of complexitybased measures to relevant questions in the field of innovation. In fact, our patent-based green fitness offers a rich yet synthetic measure of the degree of technological development of each country, and leaves interesting questions open to investigation, such as whether countries with similar degrees of fitness tend to follow similar paths over time and whether the mix of technologies observed in a country at a given point in time lead preferentially toward the expansion in a well-defined set of new fields. Additionally, based on the export specialization profiles of countries, the EFC metric has already proven to be a valid tool in inferring a country's manufacturing capabilities and in linking its potential of growth with its productive structure. Therefore, our measure of green technological fitness can provide additional information on the trajectories of national innovation systems, and, if put into relation with the export fitness, it could provide an even more nuanced representation of growth and development possibilities.

The empirical analysis yields two main findings. First, income inequality exhibits significant negative correlation with countries' green innovation capacity. This suggests that, on average, the development of more complex green technological capabilities is mainly concentrated in countries characterised by low levels of inequality. A possible explanation can be extrapolated from the literature on the determinants of green innovation. First, 
higher complexity also entails higher costs and uncertainty in the knowledge generation process that characterises exploratory activities. Second, high inequality is detrimental to innovation since the externalities from the rich, pioneer consumers are lower. Combining these two aspects, we point out that the unequal distribution of income lowers the benefits arising from the development of complex technological capabilities. By exploring this relationship through a non-parametric approach, we shed light on the non-linear relationship between inequality and innovation. Our conjecture is that this relationship differs according to the levels of inequality and the countries' wealth.

The second finding stems from the non-parametric approach: for high income countries, low levels of inequality are associated with higher capabilities in the development of more complex green technologies. In addition, increasing the level of inequality does not appear a barrier to green technologies. Instead, a moderate level of inequality facilitates specialisation in more complex technological fields. This is ascribed to the pioneer consumer effect. Moreover, low income inequality makes it possible also for countries with intermediate levels of per capita income to develop the capabilities necessary to increase their capacity to innovate in relatively complex green technologies. This indicates that a more equal distribution of income matters for unleashing innovation capacity among both low- and mid-level income countries. Hence, high income inequality appears to be a barrier to innovation capacity especially among low- and mid-level income countries.

While we claim that the present study contains several elements of originality, we are also aware that the issues at hand are indeed complex and that the limitations of the present analysis are a compass for further research. First, the recurrent caveat in innovation studies: we have only considered inventions that are captured by patents and, while technology is touted to be a major driver of the transition to sustainable economies, it is certainly not the only one. Future research could build on our effort at mapping innovation capabilities and develop more specific narratives of the manifold transformations that are at play. Second, climate change is a global phenomenon with local manifestations, and regional or city-level variation is crucial. Third, we account for domestic capabilities only indirectly, and do not delve into the skills-innovation nexus as mediated by the institutional dynamics of the attendant labour markets. Fourth, we have not explicitly accounted for trade as a channel for green technology diffusion. Finally, we focused on income inequality but remain aware of the manifold forms of inequality that matter for environmental issues. Unequal access to environmental goods, different degrees of exposure and vulnerability to environmental risks, and uneven effects of environmental policies are other important, if hard to measure, forms. While we are aware of these limitations, we also hope that the present paper will inspire future research on this compelling agenda. 


\section{Appendix}

\begin{tabular}{|c|c|c|}
\hline Code & 1-Digit Class Description & 2-Digit Class Description \\
\hline 1 & ENVIRONMENTAL MANAGEMENT & \\
\hline 1.1 & & Air pollution abatement \\
\hline 1.2 & & Water pollution abatement \\
\hline 1.3 & & Waste management \\
\hline 1.4 & & Soil remediation \\
\hline 1.5 & & Environmental monitoring \\
\hline 2 & WATER-RELATED ADAPTATION TECHNOLOGIES & \\
\hline 2.1 & & Demand-side technologies (water conservation) \\
\hline 2.2 & & Supply side technologies (water availability) \\
\hline 4 & $\begin{array}{l}\text { CCMTS RELATED TO ENERGY GENERATION, TRANSMIS- } \\
\text { SION OR DISTRIBUTION }\end{array}$ & \\
\hline 4.1 & & Renewable energy generation \\
\hline 4.2 & & Energy generation from fuels of non-fossil origin \\
\hline 4.3 & & $\begin{array}{l}\text { Combustion technologies with mitigation potential (e.g., Using fossil fuels, biomass, waste, } \\
\text { etc.) }\end{array}$ \\
\hline 4.4 & & Nuclear energy \\
\hline 4.5 & & Efficiency in electrical power generation, transmission or distribution \\
\hline 4.6 & & Enabling technologies in energy sector \\
\hline 4.7 & & Other energy conversion or management systems reducing GHG emissions \\
\hline 5 & $\begin{array}{l}\text { CAPTURE, STORAGE, SEQUESTRATION OR DISPOSAL OF } \\
\text { GREENHOUSE GASES }\end{array}$ & \\
\hline 5.1 & & $\mathrm{CO}_{2}$ capture or storage $(\mathrm{CCS})$ \\
\hline 5.2 & & $\begin{array}{l}\text { Capture or disposal of greenhouse gases other than carbon dioxide }\left(\mathrm{N}_{2} \mathrm{O}, \mathrm{CH}_{4}, \mathrm{PFC}, \mathrm{HFC} \text {, }\right. \\
\left.\mathrm{SF}_{6}\right)\end{array}$ \\
\hline 6 & CCMTS RELATED TO TRANSPORTATION & \\
\hline 6.1 & & Road transport \\
\hline 6.2 & & Rail transport \\
\hline 6.3 & & Air transport \\
\hline 6.4 & & Maritime or waterways transport \\
\hline 6.5 & & Enabling technologies in transport \\
\hline 7 & CCMTS RELATED TO BUILDINGS & \\
\hline 7.1 & & Integration of renewable energy sources in buildings \\
\hline 7.2 & & Energy efficiency in buildings \\
\hline 7.3 & & Architectural or constructional elements improving the thermal performance of buildings \\
\hline 7.4 & & Enabling technologies in buildings \\
\hline 8 & $\begin{array}{l}\text { CCMTS RELATED TO WASTE WATER TREATMENT OR } \\
\text { WASTE MANAGEMENT }\end{array}$ & \\
\hline 8.1 & & Wastewater treatment \\
\hline 8.2 & & Solid waste management \\
\hline 8.3 & & $\begin{array}{l}\text { Enabling technologies or technologies with a potential or indirect contribution to GHG miti- } \\
\text { gation }\end{array}$ \\
\hline 9 & CCMTS IN THE PRODUCTION OR PROCESSING OF GOODS & \\
\hline 9.1 & & Technologies related to metal processing \\
\hline 9.2 & & Technologies relating to chemical industry \\
\hline 9.3 & & Technologies relating to oil refining and petrochemical industry \\
\hline 9.4 & & Technologies relating to the processing of minerals \\
\hline 9.5 & & Technologies relating to agriculture, livestock or agroalimentary industries \\
\hline 9.6 & & Technologies in the production process for final industrial or consumer products \\
\hline 9.7 & & Climate change mitigation technologies for sector-wide applications \\
\hline 9.8 & & Enabling technologies with a potential contribution to $G H G$ emissions mitigation \\
\hline
\end{tabular}

Table 3: 1 \& 2-digit ENV-TECH codes and labels. 


\section{References}

Acemoglu, D. (2002). Technical Change, Inequality, and the Labor Market. Journal of Economic Literature, 40(1):7-72.

Aghion, P., Akcigit, U., Bergeaud, A., Blundell, R., and Hemous, D. (2018). Innovation and Top Income Inequality. The Review of Economic Studies, 86(1):1-45.

Balassa, B. (1965). Trade liberalisation and revealed comparative advantage. The manchester school, 33(2):99-123.

Balland, P.-A. and Rigby, D. (2017). The geography of complex knowledge. Economic Geography, 93(1):1-23.

Barbieri, N., Ghisetti, C., Gilli, M., Marin, G., and Nicolli, F. (2016). A survey of the literature on environmental innovation based on main path analysis. Journal of Economic Surveys, 30(3):596-623.

Barbieri, N., Marzucchi, A., and Rizzo, U. (2020). Knowledge sources and impacts on subsequent inventions: Do green technologies differ from non-green ones? Research Policy, 49(2):103901.

Barbieri, N., Perruchas, F., and Consoli, D. (2018). Specialization, diversification and environmental technology life-cycle. Papers in Evolutionary Economic Geography, Universiteit Utrecht, 18-38.

Barro, R. J. (2000). Inequality and Growth in a Panel of Countries. Journal of Economic Growth, 5(1):5-32.

Bathiany, S., Dakos, V., Scheffer, M., and Lenton, T. M. (2018). Climate models predict increasing temperature variability in poor countries. Science Advances, 4(5).

Cristelli, M., Gabrielli, A., Tacchella, A., Caldarelli, G., and Pietronero, L. (2013). Measuring the Intangibles: A Metrics for the Economic Complexity of Countries and Products. PLoS ONE, 8(8):e70726.

Forbes, K. J. (2000). A reassessment of the relationship between inequality and growth. American Economic Review, 90(4):869-887.

Freistein, K. and Mahlert, B. (2016). The potential for tackling inequality in the sustainable development goals. Third World Quarterly, 37(12):2139-2155.

Hartmann, D., Guevara, M. R., Jara-Figueroa, C., Aristarán, M., and Hidalgo, C. A. (2017). Linking economic complexity, institutions, and income inequality. World Development, 93:75-93. 
Haščič, I. and Migotto, M. (2015). Measuring environmental innovation using patent data. oecd.

Hausmann, R., Hwang, J., and Rodrik, D. (2007). What you export matters. Journal of Economic Growth, 12(1):1-25.

Hidalgo, C. A. and Hausmann, R. (2009). The building blocks of economic complexity. Proceedings of the National Academy of Sciences, 106(26):10570-10575.

Hidalgo, C. A., Winger, B., Barabási, A. L., and Hausmann, R. (2007). The product space conditions the development of nations. Science, 317(5837):482-487.

Hoffert, M. I., Caldeira, K., Benford, G., Criswell, D. R., Green, C., Herzog, H., Jain, A. K., Kheshgi, H. S., Lackner, K. S., Lewis, J. S., Lightfoot, H. D., Manheimer, W., Mankins, J. C., Mauel, M. E., Perkins, L. J., Schlesinger, M. E., Volk, T., and Wigley, T. M. L. (2002). Advanced Technology Paths to Global Climate Stability: Energy for a Greenhouse Planet. Science, 298(5595):981-987.

Katz, L. F. and Murphy, K. M. (1992). Changes in relative wages, 1963-1987: Supply and demand factors. The Quarterly Journal of Economics, 107(1):35-78.

Khan, B. Z. and Sokoloff, K. L. (2001). The Early Development of Intellectual Property Institutions in the United States. Journal of Economic Perspectives, 15(3):233-246.

Mealy, P. and Teytelboym, A. (2020). Economic complexity and the green economy. Research Policy, page 103948.

Mendelsohn, R., Dinar, A., and Williams, L. (2006). The distributional impact of climate change on rich and poor countries. Environment and Development Economics, 11(2):159-178.

Nadaraya, E. A. (1964). On estimating regression. Theory of Probability 6 Its Applications, 9(1):141-142.

Napolitano, L., Evangelou, E., Pugliese, E., Zeppini, P., and Room, G. (2018). Technology networks: the autocatalytic origins of innovation. Royal Society open science, $5(6): 172445$.

OECD (2011). Towards Green Growth. OECD Green Growth Studies. OECD Publishing.

Pacala, S. and Socolow, R. (2004). Stabilization Wedges: Solving the Climate Problem for the Next 50 Years with Current Technologies. Science, 305(5686):968-972.

Perruchas, François, B. N. and Consoli, D. (2020). Specialisation, diversification and the ladder of green technology development. Research Policy, 49(3):103922. 
Popp, D., Newell, R., and Jaffe, A. (2010). Energy, the Environment, and Technological Change. In Rosenberg, N. and Halland, B., editors, Handbook of the Economics of Innovation- Vol-II, pages 873-938. Academic Press, Burlington, USA.

Pugliese, E., Cimini, G., Patelli, A., Zaccaria, A., Pietronero, L., and Gabrielli, A. (2017). Unfolding the innovation system for the development of countries: co-evolution of Science, Technology and Production. arXiv preprint arXiv:170\%.05146.

Pugliese, E., Napolitano, L., Chinazzi, M., and Chiarotti, G. (2019). The emergence of innovation complexity at different geographical and technological scales. arXiv preprint arXiv:1909.05604.

Pugliese, E., Zaccaria, A., and Pietronero, L. (2016). On the convergence of the FitnessComplexity Algorithm. The European Physical Journal Special Topics, 225(10):18931911.

Quah, D., Besley, T., Blundell, R., Chesher, A., Cowell, F., Milanovic, B., Quah, D., and Quah, D. (2001). Some simple arithmetic on how income inequality and economic growth matter by.

Roberts, J. T. (2001). Global inequality and climate change. Society $\&$ Natural Resources, 14(6):501-509.

Sbardella, A., Perruchas, F., Napolitano, L., Barbieri, N., Consoli, D., Sbardella, A., Perruchas, F., Napolitano, L., Barbieri, N., and Consoli, D. (2018). Green Technology Fitness. Entropy, 20(10):776.

Sbardella, A., Pugliese, E., and Pietronero, L. (2017). Economic development and wage inequality: A complex system analysis. PloS one, 12(9):e0182774.

Sokoloff, K. L. and Khan, B. Z. (1990). The Democratization of Invention During Early Industrialization: Evidence from the United States, 1790-1846.

Tacchella, A., Cristelli, M., Caldarelli, G., Gabrielli, A., and Pietronero, L. (2012). A new metrics for countries' fitness and products' complexity. Scientific Reports, 2.

Tacchella, A., Mazzilli, D., and Pietronero, L. (2018). A dynamical systems approach to gross domestic product forecasting. Nature Physics, 14(8):861.

Voitchovsky, S. (2005). Does the Profile of Income Inequality Matter for Economic Growth?: Distinguishing between the Effects of Inequality in Different Parts of the Income Distribution. Journal of Economic Growth, 10(3):273-296.

Vona, F. and Patriarca, F. (2011). Income inequality and the development of environmental technologies. Ecological Economics, 70(11):2201-2213. 
Weinhold, D. and Nair-Reichert, U. (2009). Innovation, Inequality and Intellectual Property Rights. World Development, 37(5):889-901.

Zaccaria, A., Cristelli, M., Tacchella, A., and Pietronero, L. (2014). How the taxonomy of products drives the economic development of countries. PloS one, 9(12):e113770. 